\title{
BMJ Open The role of osteopathy in the Swiss primary health care system: a practice review
}

\author{
Paul Vaucher, Mia Macdonald, Dawn Carnes
}

To cite: Vaucher $P$,

Macdonald M, Carnes D. The role of osteopathy in the Swiss primary health care system: a practice review. BMJ Open 2018;8:e023770. doi:10.1136/ bmjopen-2018-023770

- Prepublication history for this paper is available online. To view these files, please visit the journal online (http://dx.doi. org/10.1136/bmjopen-2018023770).

Received 24 April 2018 Revised 21 June 2018 Accepted 27 July 2018

\section{Check for updates}

(c) Author(s) (or their employer(s)) 2018. Re-use permitted under CC BY-NC. No commercial re-use. See rights and permissions. Published by BMJ.

Unit of Research in Mobility \& Musculoskeletal Care, School of Health Sciences Fribourg, University of Applied Sciences and Arts Western Switzerland (HES-SO), Fribourg, Switzerland

Correspondence to Professor Paul Vaucher; paul.vaucher@hes-so.ch

\section{ABSTRACT}

Objectives The aim of this study was to describe osteopathic activity and scope of practice to understand the current and future role of osteopathy in the Swiss healthcare system.

Design A questionnaire survey that included a patient record-based retrospective clinical audit.

Setting/population 0steopaths with a national diploma $(n=1086)$ were invited by mail to participate in an online survey. Osteopathic assistants $(n=84)$ were identified through their national association.

Questionnaire The survey was constructed from previous surveys and tested for face validity with experts, osteopaths and patient representatives. The questionnaires were completed online in English, German and French between April and August 2017. Osteopaths anonymously reported information about themselves, their practice, and the treatment and care for four randomly selected patients they managed in 2016.

Results The response rate from the survey was $44.5 \%$ (521/1171). Data on osteopathic care were collected for 1144 patients and 3449 consultations. In 2016, osteopaths saw approximately $6.8 \%$ of the Swiss population for 1700000 consultations and an overall estimated cost of 200 million Swiss francs. $76 \%$ of patients sought care directly without a referral from another care provider. Few osteopaths $(<1 \%)$ work in a hospital setting and $46 \%$ work in isolation in private practice. Infants (under 2 years old) made up $10 \%$ of all patients and $9 \%$ of patients were $\geq 65$ years. Patients most commonly sought treatment for musculoskeletal conditions (81\%) with the spine being the most frequent location (66\%). Treatments also included exercise advice (34.2\%) and lifestyle management (35.4\%). Fewer than 1 patient out of 10 were referred to another health profession or provider.

Conclusions In Switzerland, osteopathic care represents an important first line management for musculoskeletal conditions that alleviates some of the burden of care in the Swiss primary healthcare system.

\section{INTRODUCTION}

Osteopathy is a form of healthcare, offering assessment, diagnosis and management for a range of health-related conditions. ${ }^{1}$ The aim of osteopathic treatment is to optimise, restore and/or maintain a person's natural structure, function and well-being. ${ }^{2}$ Osteopathy is a form of manual therapy, but additional supportive patient care and advice may also be expected as part of a package of
Strengths and limitations of this study

- This comprehensive national clinical audit survey describes osteopathic practice, it is the first of its kind in Switzerland.

- The study achieved a $45 \%$ response rate from all osteopaths with a national diploma.

- Retrospective clinical audits may reflect standards of record keeping not actual care.

- Prospective clinical audit allows for gathering the patient perspective which this study lacks.

care. $^{3-5}$ Typically, osteopaths treat musculoskeletal disorders such as back and neck pain, but they also treat other non-musculoskeletal conditions such as digestive disorders and headaches. ${ }^{67}$ Osteopathy is perceived as safe, serious treatment reactions following osteopathic care are extremely rare (1 per 36000 consultations) and concern 1 out of 24 osteopaths yearly. ${ }^{8}$

Regulation and state recognition of osteopathy varies between countries in Europe, but osteopathy is widely practised in Europe. The Osteopathic International Alliance (OIA) estimated that there were approximately 40000 practising osteopaths in the European Union (4000 in the UK, 17460 in France, $5000-6000$ in Italy and a further 5000-7000 in Germany in 2013). ${ }^{2}$

In Switzerland, osteopathy has gained in popularity since the $90 \mathrm{~s}^{9}$ and generally is well accepted in the healthcare system. ${ }^{10}$ On the 7 June 2016, the Swiss federal government formally recognised osteopathy as a health profession within the Swiss healthcare education system. ${ }^{11}$ In January 2017, there were 1086 osteopaths certified to practise in primary care in Switzerland with a Swiss Conference of Cantonal Health Directors (GDK-CDS) diploma. ${ }^{12}$ This diploma is delivered by the GDK-CDS and entered in the National Register of Healthcare Professions (NAREG) after an assessment by an intercantonal commission. ${ }^{13}$ Since 2014, Osteopaths have been trained to master's level at the University of Applied Sciences and Arts 
Western Switzerland (HES-SO). Practising osteopaths, like other primary healthcare professionals in Switzerland, ${ }^{14}$ operate fairly independently in the private sector. Little is known about osteopaths and their practice postcertification, this contributes to a lack of understanding about the profession by the public and other healthcare professionals. ${ }^{15}$ This knowledge is necessary for optimising resource utilisation and integrating the profession in the healthcare system.

The nature and type of osteopathic care provided varies not only between individual osteopaths, but also between countries in Europe and also internationally. ${ }^{16-22}$ This diversity makes it difficult to clearly define osteopathy and osteopathic care. Understanding osteopathic care as it is delivered should help describe osteopathy. ${ }^{2}$ The aim of this study was therefore to describe osteopath profiles, practice and care, as reported by osteopaths. This will enhance our understanding of the profession generally and of the healthcare osteopaths provide in Switzerland.

\section{METHODS \\ Design}

This was a questionnaire survey and osteopathic practice clinical audit review, which is a type of service evaluation. ${ }^{23}{ }^{24}$ We chose to do a retrospective clinical audit of patient data to review actual practice and clinical record keeping rather than to influence practice by doing a prospective review. The survey was conducted between April and August 2017.

\section{Studied population}

All osteopaths with a GDK-CDS diploma listed on the NAREG database ${ }^{13}$ in January 2017 and all assistant osteopaths who were registered with the Swiss Federation of Osteopathic Assistants (SVOA-FSOA) were invited by mail to participate in an online survey. Osteopathic assistants are those preparing to take their GDK-CDS diploma. The two main professional bodies, the Swiss Federation of Osteopaths (SVO-FSO) and OSTEO-SWISS, approved and promoted the study among their members.

\section{Questionnaire development and testing}

To investigate osteopaths' scope of practice, we developed a questionnaire that was organised in two separate sections; one to collect information about the osteopaths (31 questions), and the second for them to report anonymised information drawn from their patient records (47 questions). The first section focused on describing osteopaths' demographics, osteopathic workload and working environment, interdisciplinary collaborations. The second section focused on patient demographics and comorbidities, main types of presenting conditions osteopaths manage as primary care practitioners, the nature and type of examinations and treatment they provide, the way they obtain consent for examination and treatment, the costs and insurance coverage for treatments, the frequency and reasons for referrals to other health professionals, and undesired treatment reactions. The questionnaire was constructed in English from questions used in previous surveys. ${ }^{216-22} 25$ Question were selected and adapted to the Swiss context. Questions were closed except when the option 'other' was selected. The first section was estimated to take $10-15 \mathrm{~min}$ to answer, whereas the second was estimated to take 5-20 min for each patient. The questionnaires in English, German and French are available for download at https://zenodo.org/communities/osteosurvey.

The validation process included four steps with different contributors providing information on the questionnaire through structured interviews, a think-aloud approach, pilot testing and assessing quality of reporting.

Six osteopaths were asked to read and reflect on the first English version of the questionnaire and provide feedback during a 1-2 hour structured interview. At each step, the questionnaire was improved and re-tested. We then used a 'think aloud' pilot testing approach with three osteopaths before having the questionnaire professionally translated into French and German. We then pilot tested the final translated questionnaire, and members of SVO-FSO commission and cantonal associations committees responded to the questionnaire and provided feedback. The 'Do not know/not on the record' response frequencies were analysed to modify the questionnaire where appropriate, and improve the data collected. We also tested whether responders were able to provide data relating to the questions from patient records. Five osteopaths were selected from our peer networks to return one anonymised patient record. Two research collaborators then analysed records to assess the quality of reporting prior to launch.

\section{Procedure}

Osteopaths and osteopathic assistants received a personalised mail containing an information leaflet and a letter inviting them to participate in an online survey. Once invitees gave their consent to participate, the first part of the questionnaire asked them to provide information about themselves and their practice. They were then asked to answer the second part of the questionnaire in which they were asked to report how they had managed four patients they had started to treat in 2016. To be reported, cases had to be: new patients, patients with a new presenting condition or patients with a new episode of a previous condition. A random date generator was embedded in the questionnaire software. Osteopaths were asked to select the first patient that fitted the inclusion criteria in the 24-hour period that followed the provided time frame (eg, 14:00 to 17:00 time frame on 13 March 2016). If there were no patients that fitted the inclusion criteria, then the osteopath generated another random date using the random date selector until they located an appropriate patient. Using their patient record, they were then asked to extract anonymised data about the patient's age, sex, working status, payment method, presenting condition, health profile, consultation structure, processes (eg, consent), examinations, treatment and referrals for 


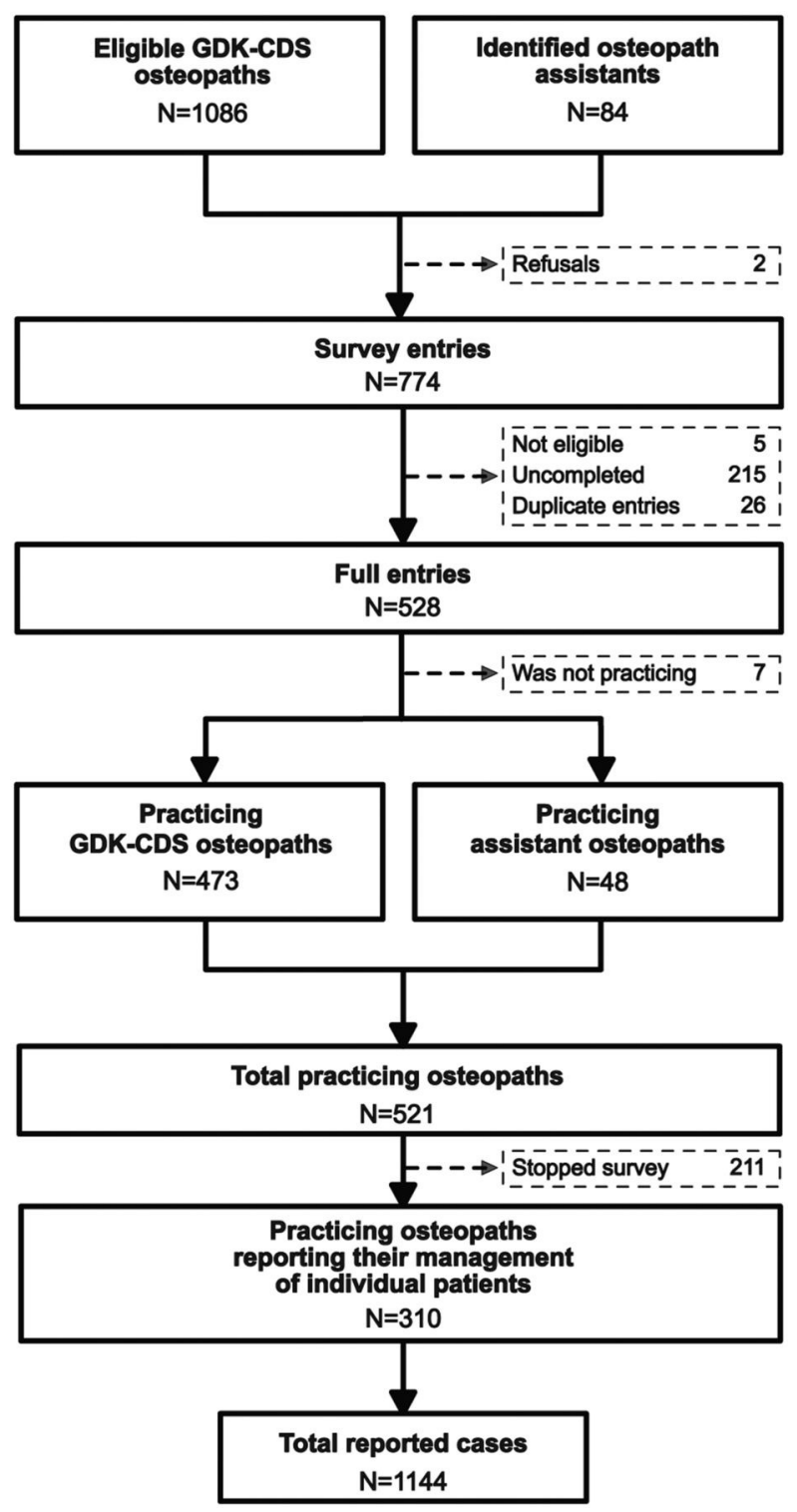

Figure 1 Flow chart illustrating data source for the practice review. GDK-CDS, Swiss Conference of Cantonal Health Directors.

other examinations, tests or treatment. Data from patient records were separated from the osteopath's data so it was impossible to assign or associate patient data with the osteopath. Osteopaths were awarded a certificate for 4 hours of continuous professional development (CPD) once they completed the entire survey.

\section{Monitoring and maintaining recruitment rates}

Quality control and data monitoring were ensured during the entire period of data collection running from April to August 2017. Weekly reports on recruitment rates were updated on the webpage and three reminders were sent to all osteopaths who had not completed/submitted the questionnaire. A bilingual hot-desk was made available 5 days a week by phone and responses to emails were sent within 24 hours.

\section{Data management}

Data were collected using an online questionnaire system called REDCap, managed by the HES-SO and hosted on a secured server at the School of Engineering and Architecture, Fribourg. Sample size was estimated from a pilot study. ${ }^{25}$ We expected a $28.1 \%$ response rate; to have a $5 \%$ margin of error with CIs of $95 \%$ for conditions that have at least a $5 \%$ prevalence, we therefore needed to include at least 1365 health records. Expecting 10\% missing data, the total number of planned records needed to analyse was rounded to 1500 . Outliers or missing responses were avoided by having the online entry system REDCap notify users when values were out of boundaries or ranges or when a question remained unanswered. Open answers for 'other' options were grouped in themes depending of content by a research assistant and then validated by a qualified osteopath with research experience. Partially answered questionnaires were excluded from analysis. Duplicate questionnaires (osteopaths who responded twice to the survey) were detected through content analysis and only the most recent entries were retained.

\section{Patient and public involvement}

An oversight committee of three members, one from the SVO-FSO, one from the SVOA-FSOA and a patient with interest in osteopathy from the Swiss Federation of Patients, overviewed the entire process. Their feedback was requested to define the study design and validate changes brought to the study material by the research team. Practitioners and stakeholders from professional associations contributed in testing and providing feedback on the content of the questionnaires. A webpage (www.osteosurvey.org) was set up for potential respondents to find supplementary information on the study. All study material (ie, study protocol, budget, questionnaires and ethical official decisions) was openly made available to patients, osteopaths and the general public in total transparency. Patients were informed of the study using an informative flyer placed in clinic waiting rooms. Patients and osteopaths were invited to provide feedback, comments, complaints or report difficulties to the research team. Using an opt-in approach, participating osteopaths were sent a copy of the study report by email. The report and study publications are made publicly available by the Swiss Osteopathy Science Foundation and on a data repository site.

\section{Consent and confidentiality}

All osteopaths were informed about the nature and purpose of the study and were given the opportunity to contact the research team for further information. All responders agreed to take part in the study and gave their informed consent for the data to be used and analysed for publication. All data were fully anonymised at entry. Names and email addresses for CPD certificates were entered separately from other data. The procedures were in accordance with the Declaration of Helsinki as revised 2013. 


\section{RESULTS}

\section{Response rate and representativeness of sample}

In January 2017, there were 1086 osteopaths who had a GDK-CDS certificate in Switzerland and we estimated there were a further 80-90 assistant osteopaths working under the supervision of a GDK-CDS osteopath. Overall there are around 12.9 certified osteopaths per 100000 residents in Switzerland. The distribution is not even throughout the country with a density that is three times higher in the French speaking part of Switzerland compared with the German speaking part. The responding osteopaths represented $44.5 \% \quad(n=521)$ of the estimated total number of certified GDK-CDS osteopaths and osteopathic assistants in Switzerland (figure 1). Of these, 473 were GDK-CDS osteopaths $(43.4 \%$ of all GDK-CDS osteopaths) and 48 were osteopathic assistants ( $53 \%$ of osteopathic assistants). The responding osteopaths reported data on 1144 patients and 3449 consultations. Our sample was representative of osteopaths for gender and geographical localisation, but osteopaths who were not a member of a professional association were under-represented (25/261).

Most of the patients' records reviewed (73\%, $n=835 / 1144)$ were randomly selected from the first random date choice given and were evenly represented throughout the year. There was an average of $10 \%$ of the sample per calendar month with $12 \%$ of patient sample seen in June (uppermost range) and 6\% in December.

\section{Demographics of practising osteopaths in Switzerland}

Osteopaths had a median experience of 11 years of practice (range $<1$ to 36 years). The profession is represented by a majority of women $(54.7 \% ; n=285 / 521)$, with older osteopaths tending to be represented by more men (figure 2). The most common degree of qualification is a diploma obtained in Switzerland (table 1). There are more osteopaths working in the French-speaking part of Switzerland and in urban areas (table 1).

\section{Working conditions}

Most osteopaths in this survey were self-employed (table 1); one-fifth were working as employed assistants (assistants could work in multiple practices as either

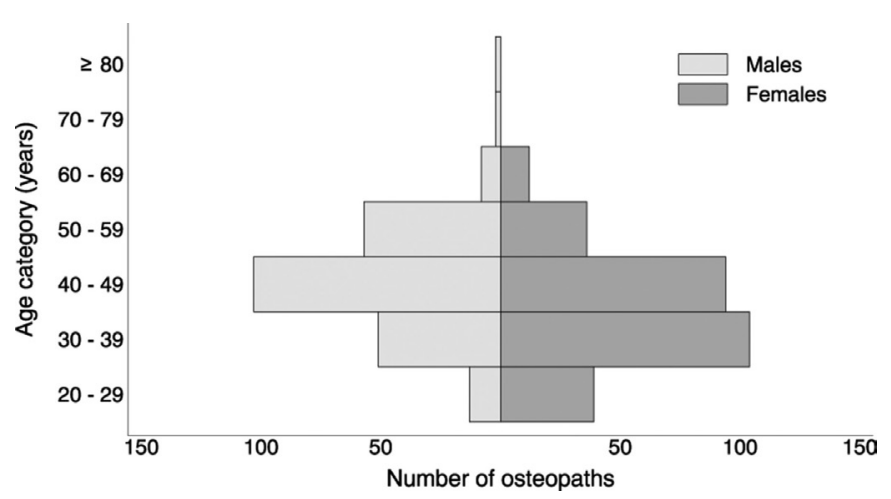

Figure 2 Age and male to female estimated distribution of osteopaths in Switzerland. self-employed or employed with or without a GDK-CDS diploma). Our survey indicated that $46.1 \%(n=240 / 521)$ osteopaths worked exclusively on their own, $14 \%$ $(\mathrm{n}=73 / 521)$ occasionally worked with others and $39.9 \%$ $(n=208 / 521)$ worked with others on a daily basis. Fewer than $1 \%$ worked in a hospital setting (table 1 ).

\begin{tabular}{|c|c|}
\hline & Osteopaths n (\%) \\
\hline \multicolumn{2}{|l|}{ Years since degree } \\
\hline$\geq 2$ & $50(9.6)$ \\
\hline $3-5$ & 55 (10.6) \\
\hline $6-10$ & $164(31.5)$ \\
\hline $11-20$ & $240(46.1)$ \\
\hline$>20$ & $22(4.2)$ \\
\hline Sex: female & $285(54.7)$ \\
\hline \multicolumn{2}{|l|}{ Degree of qualification } \\
\hline Diploma & $488(93.6)$ \\
\hline Bachelor & $14(2.7)$ \\
\hline Masters & $14(2.7)$ \\
\hline Other & $2(0.4)$ \\
\hline Unknown & $3(0.6)$ \\
\hline \multicolumn{2}{|l|}{ Country of qualification } \\
\hline Switzerland & $368(70.6)$ \\
\hline France & 57 (10.9) \\
\hline Germany & $38(7.3)$ \\
\hline UK & $27(5.2)$ \\
\hline Belgium & $26(5.0)$ \\
\hline Netherlands & $1(0.2)$ \\
\hline \multicolumn{2}{|l|}{ Linguistic region } \\
\hline German speaking & $215(41.3)$ \\
\hline French speaking & $323(62.0)$ \\
\hline Italian speaking & $10(1.9)$ \\
\hline Romansh speaking & $1(0.2)$ \\
\hline \multicolumn{2}{|l|}{ Location } \\
\hline Urban & $372(71.4)$ \\
\hline Rural & $193(37.0)$ \\
\hline \multicolumn{2}{|l|}{ Employment status } \\
\hline Self-employed & $419(80.4)$ \\
\hline Assistant & $65(12.5)$ \\
\hline Associate & $41(7.9)$ \\
\hline Voluntary work & $8(1.5)$ \\
\hline Other/unknown & $16(3.1)$ \\
\hline \multicolumn{2}{|l|}{ Settings } \\
\hline Individual practice & $281(53.9)$ \\
\hline Group practice & $259(49.7)$ \\
\hline Hospital & $8(1.5)$ \\
\hline Private clinic & $12(3.3)$ \\
\hline Social care centre & $9(1.6)$ \\
\hline Home visit & $20(3.8)$ \\
\hline
\end{tabular}


In our survey, osteopaths spent most of their time in clinical activities $87.4 \%$ (median 100\%; IQR 80\%-100\%) with $8.1 \%$ of osteopaths working $\leq 50 \%$. Women were more likely to work part-time than men $(55.4 \%$ vs $26.3 \%$, $\mathrm{p}<0.001)$. Osteopaths saw around 36 patients per week (IQR 26-42), roughly 5 of these were new patients. Only a small minority of osteopaths saw patients on weekends $(13.7 \%, \mathrm{n}=71 / 521)$ or offered home visits $(3.8 \%$, $\mathrm{n}=20 / 521)$. Nearly all osteopaths $(88.5 \%, \mathrm{n}=461 / 521)$ provided their services to a wide range of the public over all ages. Only 2.3\% ( $\mathrm{n}=12 / 521)$ of osteopaths limited their practice to a specific group or type of patient (ie, $90 \%-100 \%$ of their time dedicated to children, pregnant women, sportspeople, performing artists or older adults).

\section{Patients' demographics and comorbidities}

In this sample, $57 \%(\mathrm{n}=652 / 1144)$ of patients were women. The average age for adult patients ( $>18$ years) was 45 years. Ten percent $(n=118 / 1144)$ of the sample were infants, aged between 0 and 2 years. Figure 3 shows the age profile of patients and that infants were seen mainly in the first 6 months of their lives. Fortyfive per cent $(n=515 / 1144)$ of our sample of patients were employed, 13\% ( $\mathrm{n}=149 / 1144)$ self-employed, 9\% $(\mathrm{n}=103 / 1144)$ home carers, $8 \% \quad(\mathrm{n}=91 / 1144)$ were retired, $10 \%(\mathrm{n}=110 / 1144)$ were children not at school and $14 \%(\mathrm{n}=160 / 1144)$ were still in school or higher education.

Thirty-six per cent $(n=418 / 1144)$ of patients reported having a comorbidity (conditions diagnosed by a medical practitioner). The most common were rheumatological $(8.1 \%)$, followed by digestive $(6.9 \%)$ and cardiovascular disorders $(5.4 \%)$. Forty per cent of the patients had previously seen someone else about their condition, most commonly a general practitioner $(24.1 \%)$ or physiotherapist $(11.8 \%)$. Eighty-four per cent had no days off work or school due to their condition. Over half of the patients $(54.6 \%$; $\mathrm{n}=625 / 1144)$ were seen within a week after making the appointment and $9.8 \%$ within the day.

\section{Type of conditions managed by osteopaths}

The vast majority of patients' presenting conditions concerned musculoskeletal pain $(80.9 \%$; $\mathrm{n}=925 / 1144)$, followed by gastrointestinal symptoms (10.4\%) (figure 4). The three predominant main conditions addressed by osteopaths were low back pain $(19.4 \%)$, neck pain $(19.3 \%)$ and headaches $(11.2 \%)$. Over half of patients had more than one predominant symptom area (53.9\%; $\mathrm{n}=617 / 1144)$. The most frequent location was the spinal area $(65.8 \% ; 753 / 1144)$, followed by lower extremities $(21.7 \% ; \mathrm{n}=248 / 1144)$, the head $(19.5 \% ; \mathrm{n}=223 / 1144)$, the thorax and abdominal regions $(18.4 \% ; \mathrm{n}=210 / 1144)$, and finally the upper extremities $(17.6 \%$; $n=201 / 1144)$. There was a fairly equal mix of patients with acute and subacute and chronic conditions; $45.1 \%(\mathrm{n}=516 / 1144)$ had their condition for $\leq 4$ weeks and $51.9 \%(n=594 / 1144)$ longer. One-fifth $(20.3 \%, n=232 / 1144)$ had their condition $>1$ year and $11.3 \% \quad(n=129 / 1144)>5$ years. Many

\section{A. Infants}

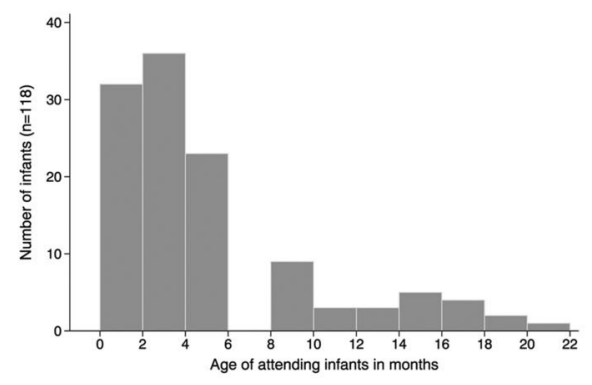

B. Children / adolescents

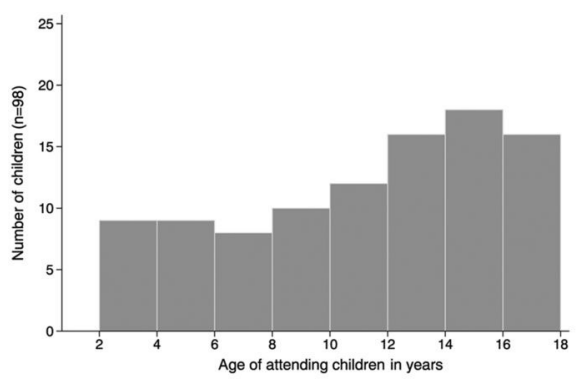

C. Adults

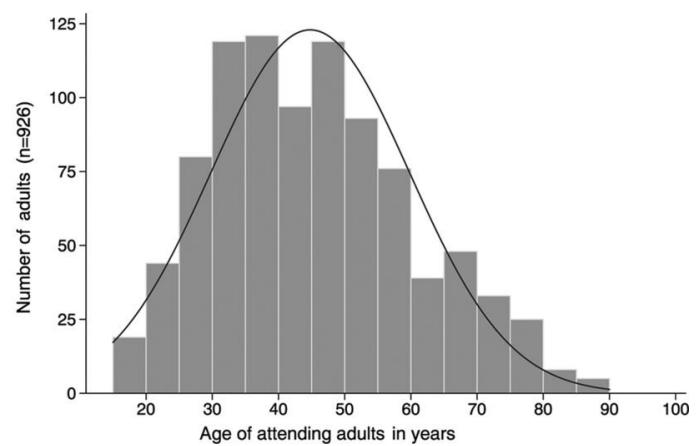

Figure 3 Age profile of patients. Age of infants are given in months (A), those for children and adolescents (B) and adults (C) in years.

patients $(36.7 \%, \mathrm{n}=408 / 1144)$ reported already being familiar with their symptoms from a previous episode. The onset of symptoms was insidious for $47.2 \%$ of patients $(\mathrm{n}=540 / 1144)$ and due to trauma for $21.3 \%$ $(n=244 / 1144)$.

\section{Clinical examination}

Examination and test results from prior consultations with other health professionals were made available to osteopaths for one out of four patients $(25.6 \%$; $n=293 / 1144)$. The most frequent reported tests were X-rays $(15.1 \%$; $\mathrm{n}=173 / 1144)$ followed by MRI (11.4\%; $\mathrm{n}=130 / 1144)$. Osteopaths saw the actual X-rays for $3.2 \%$ of cases and MRI for $2.8 \%$ of cases; $18.2 \%(n=81 / 444)$ of patients with low back pain had a previous X-ray and $14 \%(n=62 / 444)$ an MRI. Imaging was requested by osteopaths for $2.2 \%$ of patients with low back pain and $0.9 \%$ of those with neck pain. 


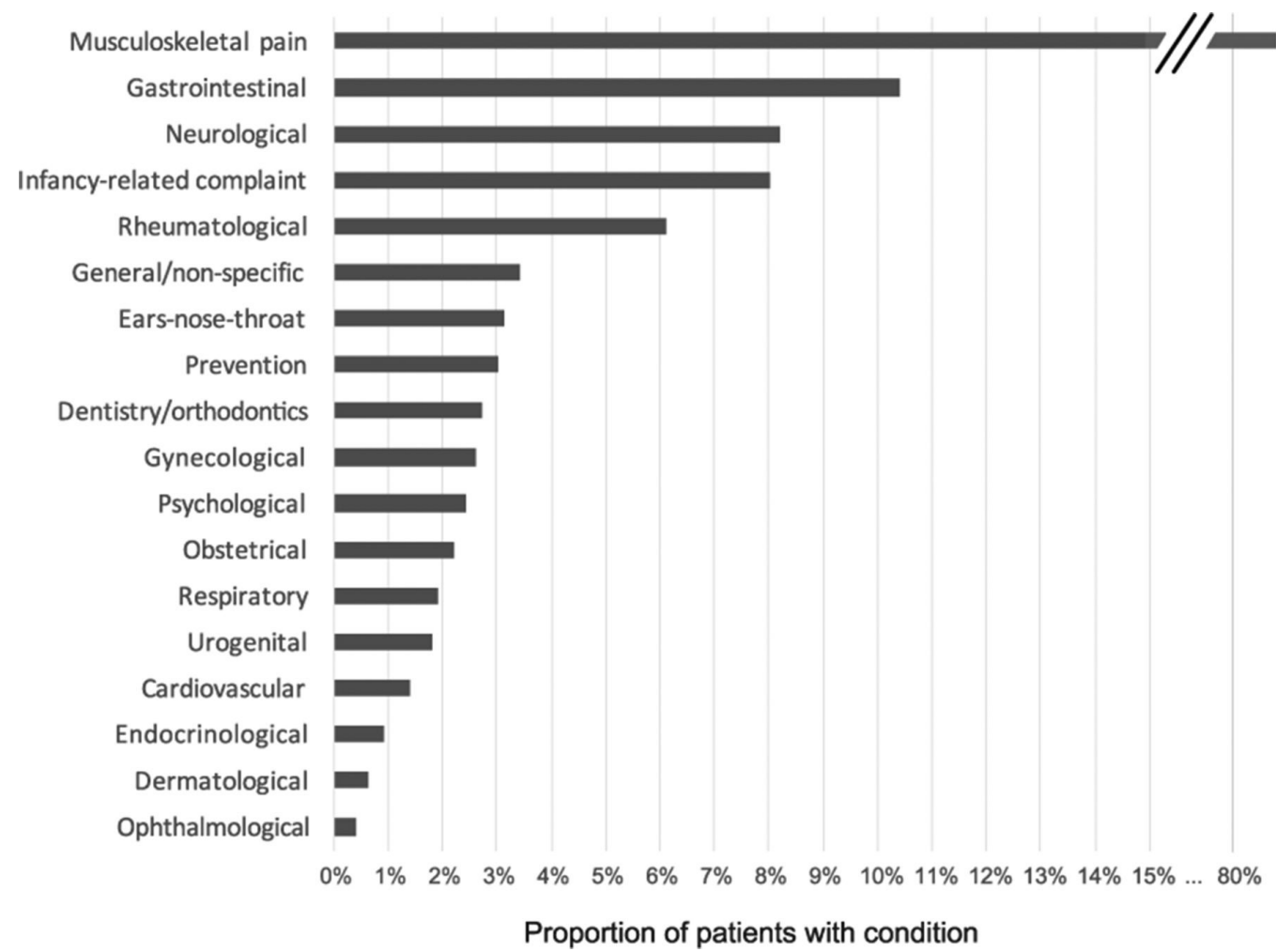

Figure 4 Type and frequency of conditions addressed by osteopaths $(n=1144)$. The figure is trunked for musculoskeletal pain to scale other types of complaints. More than one condition could be reported per patient.

The most frequently performed clinical examinations by osteopaths were palpation of position/structure $(89.9 \% ; \mathrm{n}=1028 / 1144)$, palpation of range of motion $(80.9 \% ; \mathrm{n}=925 / 1144)$, palpation of tenderness (80.3\%; $\mathrm{n}=919 / 1144)$, assessment of joint movement quality (79.2\%; $\mathrm{n}=906 / 1144)$ and observation $(74.0 \%$; $\mathrm{n}=847 / 1144)$. Osteopaths relied on orthopaedic or neurological tests, for example, neurological tests were done for $29.3 \%$ of patients with low back pain and for $27.8 \%$ of those with neck pain; and orthopaedic tests were done for $41.8 \%$ of patients with shoulder pain and for $63.5 \%$ with knee pain. During the last year, $30.1 \%(n=157 / 521)$ of osteopaths reported having performed pelvic intimate examination (ie, vaginal, rectal). However, these data were not supported in the patient data; intimate examinations were reported in fewer than $1 \%$ of patient files $(\mathrm{n}=8 / 1144$; six vaginal and two rectal).

\section{Treatment}

Nearly two-thirds of patients were only seen once $(31.3 \%$; $\mathrm{n}=353 / 1144)$ or twice $(30.4 \%$; $\mathrm{n}=343 / 1144)$ for the given episode and only 1 patient out of 20 was seen eight times or more. The median duration of follow-up was 2 weeks (range 0 to 78 weeks). However, $17 \%$ of patients $(n=194 / 1144)$ were still in the process of being treated for their condition at the time of the survey.

Patients received a wide range of therapeutic care approaches that included osteopathic manipulative treatment (99.0\%; $\mathrm{n}=1132 / 1144)$, exercises (34.2\%; $\mathrm{n}=391 / 1144)$, psychological and lifestyle management
(35.5\%; $\mathrm{n}=406 / 1144)$, and adjunct therapy (3.9\%; $45 / 1144)$. Osteopaths reported providing care aimed at patient self-management of their symptoms $(93.8 \%$; $\mathrm{n}=1073 / 1144$ ). Figure 5 provides detail on the therapeutic approaches used.

\section{Discussion with patient and consent}

Osteopaths provided an explanation of the presenting condition for $75.2 \%(\mathrm{n}=858 / 1144)$ of their patients. They also discussed treatment options with $82.6 \%$ $(\mathrm{n}=944 / 1144)$ of their patients, risks and side effects with $78.3 \%$, anticipated responses to treatment with $90.9 \%$ and the anticipated number of treatments with $72 \%$.

For $60 \%$ of patients, consent for examination or treatment was considered as implied. Osteopaths reported obtaining explicit consent from $35.4 \%(\mathrm{n}=405 / 1144)$ of patients for examinations and from $37.2 \% \quad(n=425 / 1144)$ for treatments. For the eight cases with intimate pelvic area examination, verbal consent was obtained for five cases, written consent for one and implied consent for two.

\section{Cost and insurance coverage}

The reported planned median duration of consultations was $45 \mathrm{~min}$ (range $30-90 \mathrm{~min}$ ). This duration was similar whether the attending patient was new, returning for a new condition or been followed-up for a given condition. Fees for new patient consultations ranged between IQR 120.-; 150.-, median CHF 120.- for standard consultations, CHF 100.- (IQR 80.-; 120.-) for short emergency consultations, and CHF 130.- (IQR 120.-; 150.-) for home visits. 


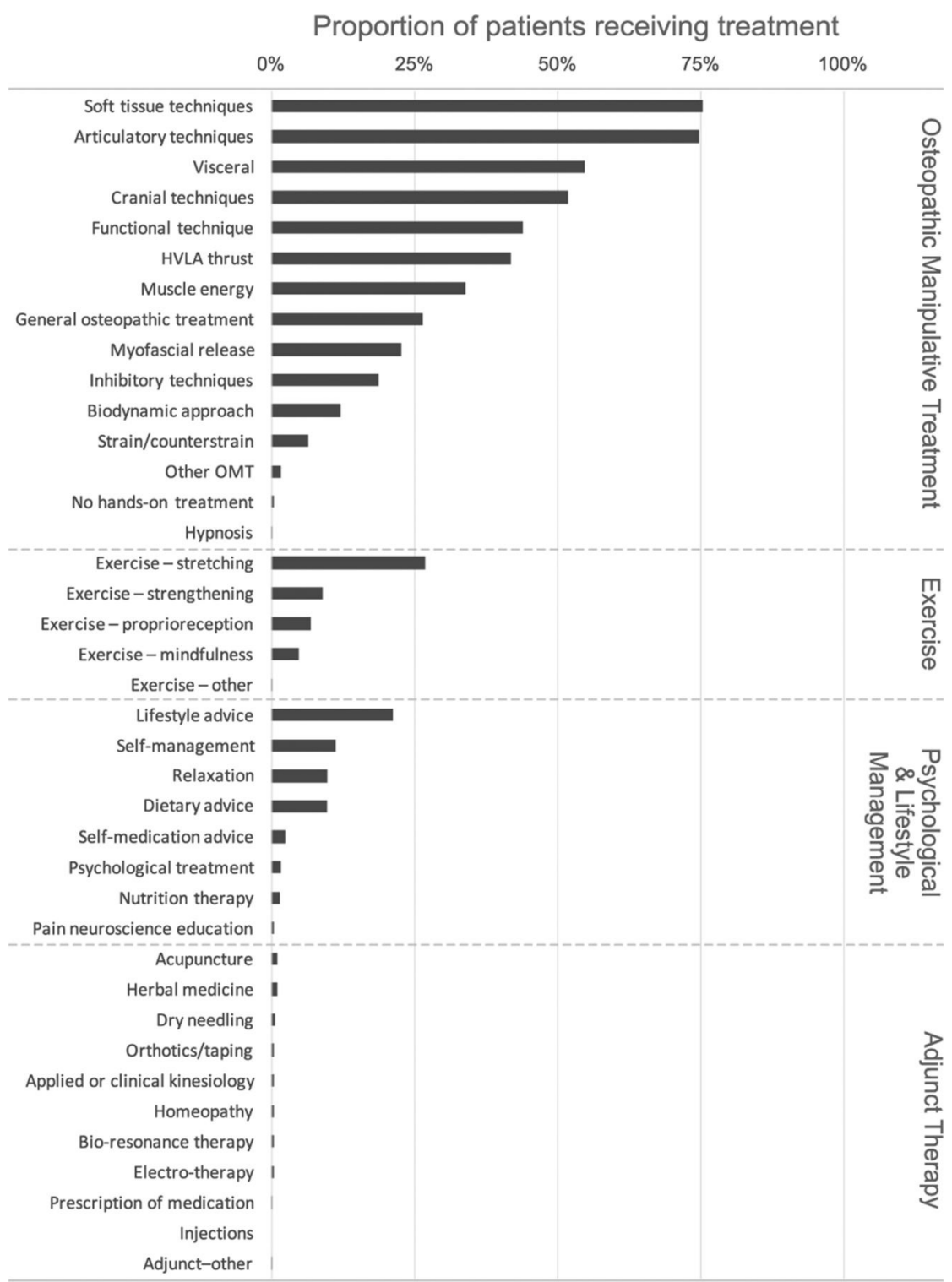

Figure 5 Proportion of patients $(n=1144)$ having received specific treatments by osteopaths. High velocity low amplitude (HVLA), Osteopathic manipulative treatment (OMT)

At the time of the study, 1.- CHF was worth approximately 11US1\$, $0.90 €$ and $0.80 £$

Payment for osteopathic care in $80 \%$ of cases $(\mathrm{n}=915 / 1144)$ was from insurance cover with $14 \%$ paying privately. For patients less able to pay full fees, $80.5 \%$ $(n=338 / 521)$ of osteopaths gave price reduction.

\section{Referrals}

Three quarters of the patients $(76 \%)$ came direct to the osteopath without a referral from another care provider. The remaining patients $(18 \% ; n=202 / 1144)$ were referred by, in order of frequency: their GP, midwife, a complementary therapist, a different osteopath or a physiotherapist.

Few medical specialists referred patients to osteopaths, but conversely osteopaths rarely referred to other professionals either. Only 9\% ( $\mathrm{n}=106 / 1144)$, around half the number of patients referred to an osteopath, were referred to another healthcare professional or provider. Fewer than $1 \%$ were referred to either accident and emergency, another osteopath, an orthodontist/dentist or a psychologist. Around $1 \%$ were referred to a medical specialist consultant $(\mathrm{n}=14 / 1144)$ or complementary therapist $(\mathrm{n}=15 / 1144)$.

\section{Undesired treatment reactions}

One serious adverse event was reported by an osteopath, but we do not know what it was given the osteopath did not answer the question on its nature. Treatment adverse reactions were reported for 465 of the 791 returning patients $(58.8 \%)$, they were minor and transient, such as fatigue $(11.9 \%$; 94/791), increased pain $(7.2 \%$; $=57 / 791)$, headache $(2.5 \% ; \mathrm{n}=20 / 791)$, stiffness $(1.1 \% ; \mathrm{n}=9 / 791)$ and dizziness/nausea $(0.7 \% ; \mathrm{n}=6 / 791)$. Adverse reactions to treatment may have been under-reported given that some patients with adverse reactions might have decided not to continue their treatment without informing the osteopath of the reason. 


\section{DISCUSSION}

The sample was reasonably representative of Swiss osteopathic care, we had a $44.5 \%$ response rate and the participating osteopaths were distributed throughout Switzerland. The average number of consultations per care seeking episode was two. Access to care was privileged for those covered by private insurances $(85 \%)$. Osteopathic care is mainly provided as ambulatory care in the private sector for musculoskeletal conditions $(81 \%)$ with the spine being the most common location $(66 \%)$. Osteopaths did not limit their treatment to manual therapy but also relied on education, counselling, lifestyle advice, psychological support and selfmanagement solutions.

From our data, we are able to discuss the health contribution of osteopathic care currently and in the future, the economic implications, the challenges for the profession and areas for development.

\section{Contribution to primary care health service provision}

In Switzerland, like in other countries, ${ }^{16-19}{ }^{26}$ over four out of five osteopathic patients seek care for musculoskeletal conditions. When generalising our observations to the entire population, we estimate that osteopaths provide around 1700000 consultations per year to an estimated 566666 people. This represents $\sim 6.8 \%$ of the Swiss population ( 8.3 million). Swiss osteopaths function as primary care practitioners. They often provide clinical advice and care in a community setting, where people can self-refer. Given the predicted decline in general practitioners in Switzerland ${ }^{27}$ and an ageing population with increasing prevalence of long-term conditions, ${ }^{28}$ there is likely to be a shortage of primary healthcare. Osteopaths are trained to screen, diagnose and recognise when to refer patients to specialist care. They are ideally placed in primary care to triage patients. The direct route used by patients to seek osteopathic care could therefore potentially reduce the planned increased burden of ambulatory care for other healthcare professions. ${ }^{29}$ Our results suggest that there is little risk of over-treatment and other studies have confirmed the safety of osteopathic management. ${ }^{30}$ This is particularly relevant for low back pain management, the care offered by osteopaths is compatible with the most recent guidelines. ${ }^{31} 32$

During the last decade the osteopathic profession in Europe and Australasia seems to have initiated a shift, moving beyond the biomechanical approach of musculoskeletal conditions to a broader management that also recognises the psychosocial dimensions of health ${ }^{133} 34$; patient-centred care, ${ }^{35}$ self-management ${ }^{36}$ and patient education. These elements are being increasingly recognised as contributing to the health of a nation. ${ }^{37}$

\section{Economic implications}

Ambulatory primary care physicians delivered approximately 40 million consultations in $2015 .{ }^{14}$ Musculoskeletal conditions are the most common reason to visit a doctor and generate $13 \%-18 \%$ (8.7-11.4 billion CHF) of all healthcare costs in Switzerland. ${ }^{38}$ From our survey, we estimate that in 2016, Swiss GDK-CDS osteopaths delivered approximately 1700000 consultations at an average cost of CHF 120.-. In 2012, a different survey ${ }^{39}$ estimated that $6.8 \%$ of the population aged $\geq 15$ years had attended an osteopath during the prior 12 months with an average of 3.7 consultations. Using data from this other study ${ }^{39}$ and ours, we estimate that the overall expenditure on osteopathic care in Switzerland is approximately CHF 200 million per annum. However, we are unable to comment on the cost-effectiveness of osteopathy or manual therapy in general as the evidence is lacking due to the small number of studies on the subject. ${ }^{40}$

In Switzerland, all residents have to be covered by a health insurance as defined by law (KVG/LaMAL). Premiums depend of regions and level of deductibles (excess payments) but costs approximately 200-300 CHF. (£200) per month per person with yearly deductibles ranging from 300.- to 2000.- CHF. before the insurance payments are activated. Osteopathic care is not refunded by the compulsory health insurance. To be covered, supplementary private insurance is required. These insurances usually do not have a deductible and cover between $70 \%$ and $100 \%$ of costs related to osteopathic care. In 2012, $60 \%$ of the adult population had this additional cover. ${ }^{39}$ In our survey, osteopaths reported that $80.5 \%$ of their patients were covered by a supplementary private insurance. This could mean that access to care for older patients and those with pre-existing conditions could be limited, since they are unable to obtain cover through supplementary insurance.

\section{Challenges for the profession}

Our survey revealed four major challenges for the profession; (1) meeting future needs for professional training, (2) upholding and monitoring standards and quality of care with professionals working in isolation, (3) improving the quality of record keeping and (4) improving consent and shared decision making with patients.

1. Meeting future needs for professional training: the School of Health Sciences Fribourg, division of osteopathy, is currently the only recognised higher education institution provider for Osteopathy in Switzerland. From 2019 onwards, it will produce 20-30 new graduates per year with a master's level qualification. This is in line with the European Standards for Osteopathic Services that recommends European countries provide education to level 7 standard in the European Qualification framework (ie, equivalent to a master's degree) ${ }^{4142}$ Should the profession wish to maintain the current provision of 13 osteopaths per 100000 people, it may need to consider training more osteopaths considering the expected attrition rates for retirements, population growth (estimated expansion to 9 million in 2025) ${ }^{28}$ and the gender shift towards more female osteopaths 
(the data indicated that women see $30 \%$ fewer patients than men). Furthermore, the data indicated that there were few osteopaths in Switzerland with recognised, standardised qualifications accredited at university level such as a bachelor, master or $\mathrm{PhD}$ (only $7.9 \%$ of registered osteopaths have a master's degree or above). It is important for the credibility of the profession that universally recognised qualifications are awarded to ensure that the professional training given is comparable with other healthcare professions. The new division at the School of Health Sciences Fribourg is already leading in this area, with the development and implementation of the BSc and MSc in osteopathy. Considering the shortfall in recognised qualifications in the practicing osteopathic population, there is an opportunity to provide further education.

2. Upholding and monitoring standards and quality of care with professionals working in isolation: nearly half $(46 \%)$ of the osteopaths respond to the survey practise in isolation. This has implications for patient protection and the surveillance, maintenance and regulation of osteopathic standards of practice. Safeguarding patients is paramount for the credibility and image of any healthcare profession. The osteopathic profession generally benefits from having good public trust and high levels of patient reported satisfaction, ${ }^{43}$ but the profession cannot rely on this alone to support reputation and practise. Clinical governance and surveillance of lone practitioners largely centres on patients and their willingness to report dissatisfaction with health service provision. However, in the absence of any complaints or concerns raised by patients to regulatory or official organisations, we cannot assume that healthcare provision is of a high quality and/or delivered at an acceptable standard. The issue of patient safeguarding with lone practitioners is not new. Recommendations to protect patients include: practice review, peer review, continuous professional development, obligations to clearly display complaints procedures to patients, monitoring complaints and protecting whistle blowers (colleagues who report poor, dangerous or unsafe practices). There is scope for improving the professions understanding about the outcomes of care, by collecting patient reported outcomes. This information would be useful to inform practitioners about the care and services that they provide to reflect on their practice and personal development.

3. Improving the quality of record keeping: the survey of patient records illustrated that while a lot of data were recorded about the patient consultations, they were not always comprehensive. Records were not complete for $11.5 \%$ of the patients ('Do not know/cannot tell from the record' option). There is opportunity for developing patient record keeping, to comply with expected minimum standards ensuring that records are legible, indelible, clear, unambiguous and chronolog- ically accurate. ${ }^{44}$ This could also help communicate about treatment plans with patients and other health professionals.

4. Improving consent and shared decision-making with patients: the survey showed that the practice around obtaining and recording consent are not fully developed. Gaining consent is a fundamental part of practice and is both an ethical and legal requirement. ${ }^{45}$ Consent should be an ongoing process and needs to be informed, that is, osteopaths need to provide information about effectiveness, risks and alternative treatments. ${ }^{46}$ Decisions about care can be complex and the process of consent can be daunting for both the clinician and the patient. It is good practice to develop these skills from the outset during training and raise awareness of the importance of following professional recommendations when examining intimate areas.

\section{CONCLUSIONS}

Osteopaths make a fairly substantial contribution to primary healthcare provision to a diverse population. Most care is provided for musculoskeletal conditions. There are opportunities for further education, improved record keeping and consenting procedures. Future challenges for the profession are: equal access to osteopathic care, learning to work interprofessionally and clarifying the place osteopathy has as a primary healthcare provider.

Contributors DC and PV: applied for the grant and wrote the protocol; wrote the manuscript. PV: served as principal investigator; ran the analysis. PV, DC and MM: developed and had the questionnaire validated; discussed the results. PV and MM: wrote and translated all the annexed documentation (Internet site, newsletters, invitation letters, continuous training certification); piloted the data collection and quality control. MM: cleaned and documented data cleaning. All authors provided feedback and accepted the final version.

Funding The study was funded via the Swiss 0steopathy Science Foundation (Grant 2017-R001) and by the School of Health Sciences Fribourg.

Competing interests The researchers work for the Unit of Research in Mobility at the School of Health Sciences Fribourg which includes the division of osteopathy.

Ethics approval The Lausanne Ethics Panel overviewed our protocol and the attached documents for approval (EC; 2017-00126) and concluded that Ethical Approval was not needed for this study, as all data was completely anonymised, and patient confidentiality and privacy was not compromised. All osteopathic and patient data was handled in accordance with the Swiss law on data protection (DSG/LPD 235.1). A representative of the Swiss Federation of Patients, the Federal Data Protection and Information Commissioner, and the Fribourg Cantonal Data Protection and Information Commissioner were consulted to provide their opinion on the legal aspects of the audit. Recommendations were followed to assure patients' rights were respected.

Provenance and peer review Not commissioned; externally peer reviewed.

Data sharing statement Protocol, questionnaires, statistical code and report are available on Zenodo at the following URL: https://zenodo.org/communities/ osteosurvey/. Dataset can be made available for further analysis with the approval of the University, the Swiss 0steopathy Science Foundation and the Swiss Patient Foundation.

Open access This is an open access article distributed in accordance with the Creative Commons Attribution Non Commercial (CC BY-NC 4.0) license, which permits others to distribute, remix, adapt, build upon this work non-commercially, and license their derivative works on different terms, provided the original work is 
properly cited, appropriate credit is given, any changes made indicated, and the use is non-commercial. See: http://creativecommons.org/licenses/by-nc/4.0/.

\section{REFERENCES}

1. Thomson OP, Petty NJ, Moore AP. Osteopaths' professional views, identities and conceptions - a qualitative grounded theory study. Int J Ost Med 2014;17:146-59.

2. OIA. Osteopathy and osteopathic practice; a global view of practice, patients, education and the contribution to healthcare delivery. Chicago: Osteopathic International Alliance, 2013.

3. Barnes A. Am I a carer and do I care? An exploration of the concept of care as applied to osteopathic practice. Med Health Care Philos 2004;7:153-61.

4. Cross V, Leach CM, Fawkes CA, et al. Patients' expectations of osteopathic care: a qualitative study. Health Expect 2015;18:1114-26.

5. Orrock PJ. The patient experience of osteopathic healthcare. Man Ther 2016;22:131-7.

6. Dubois T, Berthiller J, Nourry J, et al. Douleurs en cabinet d'ostéopathie : étude prospective descriptive des motifs de consultations des patients consultant en cabinet d'ostéopathie. Douleur 2012;3908:A59-60.

7. Clar C, Tsertsvadze A, Court R, et al. Clinical effectiveness of manual therapy for the management of musculoskeletal and nonmusculoskeletal conditions: systematic review and update of UK evidence report. Chiropr Man Therap 2014;22:12.

8. Vogel S, Mars T, Keeping S, et al. Clinical risk osteopathy and management scientific report. London: British School of Osteopathy, 2013.

9. Pittet C. Sondage de la perception publique de l'ostéopathie, 2005

10. Schneider S, Graz B, Rodondi P-Y, et al. Attitudes des médecins généralistes envers les médecines complémentaires et besoins de formation. Résultats d'une enquête suisse. Pédagogie Médicale 2014;15:157-60

11. Der Bundesrat. 2016. Bundesgesetz über die Gesundheitsberufe (Gesundheitsberufegesetz, GesBG). https://www.admin.ch/opc/de/ classified-compilation/20131765/index.html (accessed 4 Apr 2018).

12. GDK. Schweizerische Konferenz der kantonalen Gesundheitsdirektorinnen und -direktoren: Osteopathie. https://www. gdk-cds.ch/index.php?id=553\&L=0\&amp\%3BL=1 (accessed $4 \mathrm{Apr}$ 2018).

13. NAREG. 2018. National Register der Gesundheitsberuf. https://www. nareg.ch/ (accessed 4 Apr 2018).

14. Clausen F. Statistique des cabinets médicaux et des centres ambulatoires (MAS) - Les cabinets médicaux et centres ambulatoires en 2015. Neuchâtel: Office fédéral de la statistique, 2018.

15. Gobet J-P. Analyse de la collaboration entre médecins et ostéopathes; une enquête auprès des médecins de Suisse romande. Bulletin des Médecins Suisses 2006;87:1178-81.

16. Fawkes CA, Leach CM, Mathias S, et al. A profile of osteopathic care in private practices in the United Kingdom: a national pilot using standardised data collection. Man Ther 2014;19:125-30.

17. Burke SR, Myers R, Zhang AL. A profile of osteopathic practice in Australia 2010-2011: a cross sectional survey. BMC Musculoskelet Disord 2013;14:227.

18. Morin C, Aubin A. Primary reasons for osteopathic consultation: a prospective survey in Quebec. PLoS One 2014;9:e106259.

19. van Dun PLS, Nicolaie MA, Van Messem A. State of affairs of osteopathy in the Benelux: Benelux Osteosurvey 2013. Int J Osteopath Med 2016;20:3-17.

20. Ciulla L, Foucart J, Lepers Y. Enquète d'opinions sur la perception de l'ostéopathie au sein de la population belge francophone, 2014.

21. KPMG. Report A: how do osteopaths practice? Zurich: KPMG, 2011.

22. GOsC. Results - snapshot survey 2001. London: General Osteopathic Council, 2001.

23. Twycross A, Shorten A. Service evaluation, audit and research: what is the difference? Evid Based Nurs 2014;17:65-6.
24. Brain J, Schofield J, Gerrish K, et al. A guide for clinical audit, research and service review. London: Healthcare Quality Improvement Partnership, 2011.

25. Herzig M. An investigation into the profile of osteopaths practicing in Switzerland. London, British School of Osteopathy,2010

26. Alvarez Bustins G, López Plaza PV, Carvajal SR. Profile of osteopathic practice in Spain: results from a standardized data collection study. BMC Complement Altern Med 2018;18:129.

27. Arditi C, Burnand B. Démographie médicale : indicateurs et observatoires. Revue des pratiques en Suisse et ailleurs. Lausanne: Institut universitaire de médecine sociale et préventive (CHUV), 2014.

28. Trippel M, Groth H. Demographic Shifts in EU 27, Norway and Switzerland: population and dependency ratio forecasts until 2030 , 2011. The WDA-HSG Discussion Paper Series on Demographic Issues.

29. Seematter-Bagnoud L, Junod J, Roth $M$, et al. Offre et recours aux soins médicaux ambulatoires en Suisse - Projections à l'horizon 2030. Neuchâtel: Observatoire Suisse de la Santé, 2008.

30. Carnes D, Mars TS, Mullinger B, et al. Adverse events and manual therapy: a systematic review. Man Ther 2010;15:355-63.

31. Foster NE, Anema JR, Cherkin D, et al. Prevention and treatment of low back pain: evidence, challenges, and promising directions. Lancet 2018;391:2368-83.

32. Hartvigsen J, Hancock MJ, Kongsted A, et al. What low back pain is and why we need to pay attention. Lancet 2018;391:2356-67.

33. Penney JN. The Biopsychosocial model: Redefining osteopathic philosophy? Int J Osteopath Med 2013;16:33-7.

34. Williams NH. Optimising the psychological benefits of osteopathy. Int J Osteopath Med 2007;10:36-41.

35. Thomson OP, Petty NJ, Moore AP. Reconsidering the patientcenteredness of osteopathy. International Journal of Osteopathic Medicine 2013;16:25-32.

36. Bonakdar RA. Integrative pain management. Med Clin North Am 2017;101:987-1004.

37. Engel S, Bräm R, Oesch P. Nationale Strategie Muskuloskelettale Erkrankungen (2017-2022. Zürich: Rheumatologica Schweiz, 2017.

38. Läubli T, Müller C. Arbeitsbedingungen und Erkrankungen des Bewegungsapparates: Geschätzte Fallzahlen und volkswirtschaftliche Kosten für die Schweiz. Switzerland: Staatssekretariat für Wirtschaft SECO, 2009.

39. Klein SD, Torchetti L, Frei-Erb M, et al. Usage of complementary medicine in Switzerland: results of the Swiss health survey 2012 and development since 2007. PLoS One 2015;10:e0141985.

40. Tsertsvadze A, Clar C, Court R, et al. Cost-effectiveness of manual therapy for the management of musculoskeletal conditions: a systematic review and narrative synthesis of evidence from randomized controlled trials. J Manipulative Physiol Ther 2014;37:343-62.

41. World Health Organisation. Benchmarks for training in traditional / complementary and alternative medicine: benchmarks for Training in Osteopathy. Geneva: WHO, 2010.

42. CEN. Osteopathic healthcare provision EN 16686:2015. Bruxel: Europeean Committee for Standardization, 2015.

43. Leach J, Cross V, Fawkes C, et al. Investigating osteopathic patients' expectations of osteopathic care: the OPEn project - Full research report. Brighton: University of Brighton, 2011.

44. Royal College of Physicians. 2015. Evidence on the quality of medical note keeping: guidance for use at appraisal and revalidation. RCP London. https://www.rcplondon.ac.uk/guidelines-policy/ evidence-quality-medical-note-keeping-guidance-use-appraisaland-revalidation (accessed 10 Apr 2018).

45. World Health Organization. A declaration on the promotion of patients' rights in europe - principles of the rights of patients in europe: a common framework. Eur J Health Law 1994;1:279-91.

46. GOsC. Osteopathic practice standards - General Osteopathic Council. http://www.osteopathy.org.uk/news-and-resources/ document-library/osteopathic-practice-standards/osteopathicpractice-standards/ (accessed 10 Apr 2018). 